\title{
Influence of Laser Marks on the Electrochemical Behaviour of the ASTM F139 Stainless Steel for Biomedical Application
}

\author{
Eurico Felix Pieretti , Maurício David Martins das Neves \\ Instituto de Pesquisas Energéticas e Nucleares (IPEN/CNEN), Av. Prof. Lineu Prestes 2242, Cidade \\ Universitária, São Paulo - SP, 05422-970, Brazil \\ *E-mail: efpieretti@usp.br
}

doi: $10.20964 / 110432$

Received: 1 February 2016 / Accepted: 5 March 2016 / Published: 1 April 2016

\begin{abstract}
The aim of this work is to evaluate the effect of a laser marking technique on the microstructure and chemical composition at the surface of the ASTM F139 stainless steel and the influence of the surface modifications on its corrosion resistance. This is one of the most frequently used biomaterial for prosthesis manufacture. The laser effect on the corrosion resistance has been evaluated by electrochemical techniques, specifically electrochemical impedance spectroscopy. It was found that the laser marking reduces the corrosion resistance by modification of the microstructure and surface chemical composition affecting the surface passive layer, comparatively to the unmarked material. The surface and chemical composition was analyzed by scanning electron microscope coupled to a highresolution field emission gun (SEM-FEG) and transmission electron microscopy (TEM) with microanalysis. TEM in areas affected by laser engraving showed a very high density of dislocations suggesting the presence of residual stresses induced by laser, decreasing the corrosion resistance of the stainless steel. Aluminum and silicon oxide inclusions were conveyed into the surface exposed to the corrosive electrolyte by melting the metallic matrix surrounding them during the incidence of the laser beam. The corrosive attack of this stainless steel matrix surrounding the oxide inclusions creates micro crevices, promoting pitting corrosion. This is the mechanism proposed to explain the increased susceptibility to localized corrosion associated to the areas affected by the laser marking process.
\end{abstract}

Keywords: Biomedical engineering, biointerfaces, laser engraving, electrochemistry.

\section{$\underline{\text { FULL TEXT }}$}

(C) 2016 The Authors. Published by ESG (www.electrochemsci.org). This article is an open access article distributed under the terms and conditions of the Creative Commons Attribution license (http://creativecommons.org/licenses/by/4.0/). 